\title{
Effects of Wood Moisture Content and the Level of Acetylation on Brown Rot Decay
}

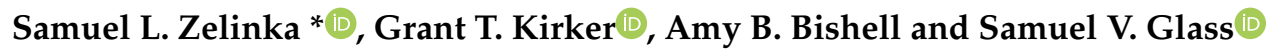 \\ US Forest Service Forest Products Laboratory, Madison, WI 53726, USA; grant.kirker@usda.gov (G.T.K.); \\ amy.b.bishell@usda.gov (A.B.B.); samuel.v.glass@usda.gov (S.V.G.) \\ * Correspondence: samuel.l.zelinka@usda.gov; Tel.: +1-608-231-9277
}

Received: 16 January 2020; Accepted: 5 March 2020; Published: 7 March 2020

\begin{abstract}
Acetylation is one of the most common types of wood modification and is commercially available throughout the world. Many studies have shown that acetylated wood is decay resistant at high levels of acetylation. Despite its widespread use, the mechanism by which acetylation prevents decay is still not fully understood. It is well known that at a given water activity, acetylation reduces the equilibrium moisture content of the wood cell wall. Furthermore, linear relationships have been found between the acetylation weight percent gain (WPG), wood moisture content, and the amount of mass loss in decay tests. This paper examines the relationships between wood moisture content and fungal growth in wood, with various levels of acetylation, by modifying the soil moisture content of standard soil block tests. The goal of the research is to determine if the reduction in fungal decay of acetylated wood is solely due to the reduction in moisture content or if there are additional antifungal effects of this chemical treatment. While a linear trend was observed between moisture content and mass loss caused by decay, it was not possible to separate out the effect of acetylation from fungal moisture generation. The data show significant deviations from previously proposed models for fungal moisture generation and suggest that these models cannot account for active moisture transport by the fungus. The study helps to advance our understanding of the role of moisture in the brown rot decay of modified wood.
\end{abstract}

Keywords: acetylated wood; wood modification; brown rot decay; fungal decay; soil block test; wood moisture content; soil bottle assays

\section{Introduction}

When wood is used in exterior applications it is subject to biodeterioration from wood decay fungi. Wood modifications, such as acetylation, are often used to protect wood from decay [1]. Unlike preservative treatments where the chemical treatments are targeted to repel or kill wood decay fungi, acetylation modifies many wood properties and a complete understanding of how acetylation prevents decay is a topic of active research. Ringman et al. reviewed the literature and concluded that diffusion inhibition through the reduction of void volume was the only mechanism that was consistent with all observed behaviors in modified wood [2]. Researchers have further proposed that diffusion likely occurs through regions of softened hemicelluloses and that acetylation may prevent decay by arresting diffusion by increasing the moisture-induced glass transition temperature of the hemicelluloses [3-5]. Recent work by Hunt et al. has confirmed that acetylated wood indeed has a higher relative humidity threshold for the diffusion of potassium ions [6]. Furthermore, Ringman et al. have suggested several possible alternative mechanisms for the inhibition of diffusion beyond cell wall plasticization [7].

Much of what is known about how treatments and wood modifications affect fungal decay comes from laboratory soil bottle tests, such as the American Wood Protection Association (AWPA) E-10 soil block assay, and the corresponding European tests, such as EN-113 [8,9]. In these tests, a fungal 
monoculture is cultivated in a sterile bottle with soil and a wood feeder strip and then a wood test block is added once the fungus is established. The efficacy of the treatment is typically examined by measuring the mass loss (ML) of the wood test block, which is calculated using the following equation:

$$
M L=\frac{m_{o d, p r e}-m_{o d, p o s t}}{m_{o d, p r e}}
$$

where $m$ is the mass of the specimen and the subscripts "pre" and "post" refer to the mass before and after the soil block test, respectively, and the subscript "od" stands for oven dried. Note that in this paper, the mass, $m$, includes the added mass of the acetylation chemical, where applicable. In the standard soil block tests, the wood moisture content is not controlled, but instead the soil is preconditioned to a certain moisture content (specified as a percent of the water holding capacity of the soil), and the moisture content of the wood test block is affected by capillary uptake from the soil and feeder strip, water vapor sorption from the humidity within the soil bottle, the moisture produced from the breakdown of wood polymers, and the moisture translocated from the fungus.

Soil block tests have shown that increasing the level of acetylation results in lower mass loss [10-14]. Typically, the mass loss of the test block after the test is plotted as a function of the weight percent gain (WPG, a measure of the intensity of the wood modification). An example of such a plot is shown in Figure 1a from the thesis of Forster [10]. Note that the mass used in all calculations includes the mass of the treatment chemical. These plots are helpful for determining the level of modification at which decay is negligible; however, such plots cannot give us insight as to the mechanism by which the wood modifications provide protection. In addition to measuring the weight loss caused by decay, Forster [10] also measured the moisture content at the end of the decay test and normalized to the dry mass after degradation, which we show in Figure 1b. We can see that there is a strong correlation between the moisture content and the mass loss, and, in fact, when the wood moisture content at the end of the test is plotted against the mass loss (with the WPG plotted implicitly, Figure 1c), we see that the mass loss increases with the moisture content at the end of the test.
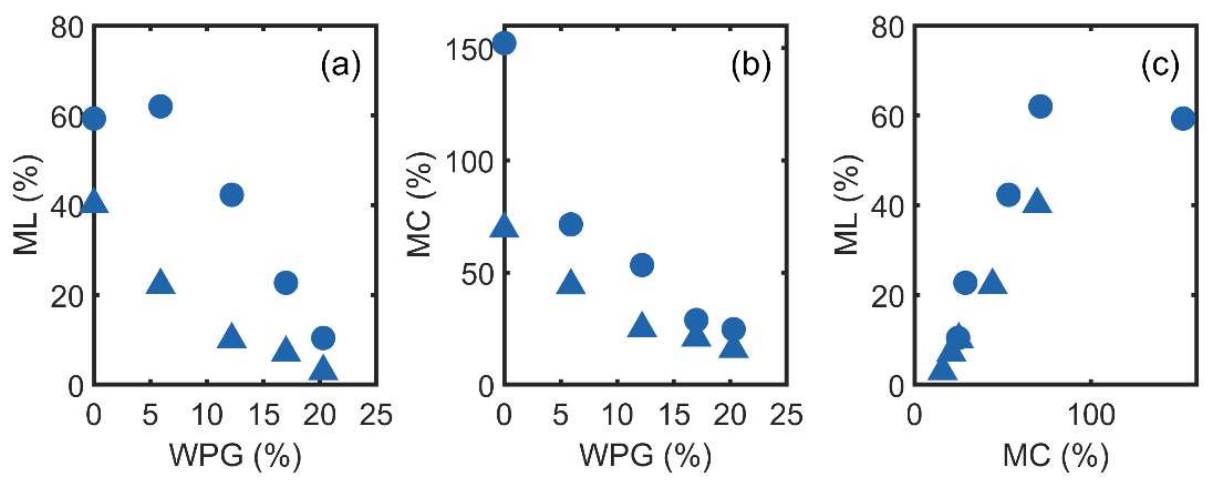

Figure 1. The interrelationship between the amount of acetylation, mass loss caused by decay, and wood moisture content at the end of the test. (a), mass loss as a function of weight percent gain. (b) final moisture content as a function of weight percent gain. (c) mass loss as a function of the final moisture content. The data replotted from Forster [10], $\mathbf{\Delta}=$ Gloeophyllum trabeum and $\bullet=$ Coniophora puteana.

The fact that the wood moisture content in soil bottle tests varies with acetylation level has important implications for understanding the mechanism of protection as well as understanding whether wood that appears to be decay resistant in soil bottle tests may be subject to decay under different environmental conditions [7]. Decay fungi are most active when the wood moisture content is between $40 \%$ and $80 \%$ moisture content (MC) [15]. In the absence of fungi, wood moisture content would depend on the water activity of the environment and the kinetics of water absorption [16]. In the soil block tests, the moisture content of the wood specimen would also depend on moisture generation from the breakdown of wood polymers by the fungus and active water translocation by the 
fungus. It has been shown that for untreated wood in the standard soil block tests, the wood moisture content increases during the first 3 weeks of the decay test and then levels off in an optimal range for fungal growth [17]. Measurements of this type are lacking for acetylated wood. Given the differences in moisture properties between acetylated and unmodified wood and the various phenomena that influence wood moisture content during decay tests, from the available literature data, it is unclear whether acetylation would provide protection against decay under higher wood moisture contents.

Thybring reviewed literature data and developed a model based upon assumed cell wall chemistry and structure that suggested that it is not surprising that wood moisture content and mass loss are correlated [18]. The model includes the theoretical amount of water produced by degradation of cellulose and hemicellulose, which is $0.56 \mathrm{~g}$ of water per $1 \mathrm{~g}$ of polymer, and is similar to an earlier model developed by Peterson and Cowling in the 1970s [19]. Thybring suggested that instead of plotting conventional moisture content as a function of mass loss, a "reduced moisture content" should instead be used where the MC is calculated with the original dry mass [18]. Since there are several definitions associated with "reduced moisture content", we use the nomenclature " $M C_{O}$ ", where the subscript stands for the moisture content calculated from the original dry mass, i.e.,

$$
M C_{o}=\frac{m_{\text {post }}-m_{o d, p o s t}}{m_{o d, p r e}}
$$

in this paper to describe the "reduced moisture content" described in the work of Thybring [18]. Thybring stated that $M C_{o}$ should be directly proportional to the mass loss as the consumption of lignocellulosic biomass results in the production of water [18]. However, Thybring did not provide additional experimental tests to confirm whether this model can fully explain the effects of moisture dynamics on decay in acetylated wood.

In this paper, we attempt to separate the moisture exclusion effects of acetylation from other mechanisms of wood protection provided by acetylation. To do this, we examine the relationship between the soil moisture content and the wood moisture content at different levels of acetylation in the presence and absence of fungus. By adjusting the soil moisture content, we are able to test different levels of acetylation at the same wood moisture content in the absence of fungus. Furthermore, performing parallel experiments with and without fungus allow us to investigate the moisture generated by the fungus.

\section{Materials and Methods}

\subsection{Materials}

Southern pine (Pinus spp.) sapwood was examined. The southern pine was cut into $10 \mathrm{~mm}$ cubes ("mini-blocks"). Four different levels of acetylation were examined: 0 WPG (control, untreated), 8 WPG, 11 WPG, and 18 WPG. The acetylation was performed in a similar fashion to our previous work $[6,20]$. Wood was vacuum-impregnated with acetic anhydride and cured in an oven at $140{ }^{\circ} \mathrm{C}$ for various times to provide a range of WPGs. The specimens were then rinsed to remove unbound acetic acid. For each different test and treatment combination.

\subsection{Soil Block Tests}

With the exception of the soil moisture content, the soil block tests followed the AWPA E-10 standard [9]. The soil bottles were made by adding soil, water, and a feeder strip of southern pine sapwood to a flint glass jar with a metal lid and autoclaving it. In this study, Rhodonia placenta (Fr.) Niemelä, K.H. Larss. and Schigel 2005 (Mad-698-R) was examined. Following the autoclave, two 5-mm plugs from the leading edge of a fungus grown on $2 \%$ malt extract plus a $0.1 \%$ yeast extract agar plate incubated in a $30{ }^{\circ} \mathrm{C}, 70 \% \mathrm{RH}$ room were placed in each bottle, one at each end of the feeder, and this was allowed to colonize the bottle for 3 weeks before introducing an autoclaved test block to the jar. The test was allowed to continue for 8 weeks, after which the blocks were removed. Prior 
to autoclaving the test block, an initial oven-dry weight was determined. After removal from the jar, the mycelia were removed, the test block was weighed, oven dried at $105^{\circ} \mathrm{C}$ overnight, and reweighed. The mass loss caused by decay was determined by Equation (1) and the moisture content after the test (MC) was determined by the following equation:

$$
M C=\frac{m_{\text {post }}-m_{o d, p o s t}}{m_{o d, p o s t}}
$$

In some experiments, the wood moisture content without the fungus was examined. In these tests, the soil, water, feeder strip, and test block were all autoclaved at the same time and the bottle was disassembled after eight weeks and the block was examined.

\subsection{Soil Water Holding Capacity}

The E-10 standard specifies that the testing should utilize a soil moisture content that is $130 \%$ of the soil water holding capacity (SWHC). For our soil, collected from an agricultural site, the SWHC was found to be $31 \%$ soil moisture content (by mass, dry basis). SWHC was varied in the tests as one of the main variables.

In the control experiments, which were intended to follow the AWPA standard, the soil moisture content prior to soil bottle preparation was not independently verified and was assumed to be the same as the previous experiment. Therefore, it was inadvertently lower than expected and, as a result, the "standard" measurements were conducted with a soil moisture content of 38.3\% MC or $124 \%$ SWHC instead of the desired $130 \%$.

In addition to the tests at $124 \%$ SWHC, additional experiments were run at $120 \%$ SWHC and $140 \%$ SHWC on all levels of the acetylated wood.

\subsection{Wood Moisture Content Preconditioning}

In preliminary experiments, the starting moisture content of the wood block was examined as another variable. It is expected that the moisture content of the blocks will change throughout the test as the specimen comes into equilibrium with the soil. If the moisture uptake of the acetylated wood has different kinetics than untreated wood, preconditioning the wood may affect the final moisture content or the amount of decay exhibited by the block. Figure 2 shows data collected at $124 \%$ SWHC for blocks that had been autoclaved in the presence of liquid water to bring their starting moisture contents above $40 \% \mathrm{MC}$; the actual MCs varied between $40 \%$ and $55 \% \mathrm{MC}$. The starting moisture content was shown to have little effect on the amount of mass loss; a t-test with unequal variance (Welch test) showed no statistical differences between the mass loss for dry and pre-wetted blocks $0 \%$, $8 \%$, and 11\% WPG ( $p=0.05)$. The final moisture content of the blocks was shown to be statistically different $(p=0.05)$ for the 8\% WPG and 18\% WPG but not the $0 \%$ and 11\% WPG conditions. Because preconditioning had such a small effect on the mass loss, except at the highest level of acetylation, it was not investigated further. 

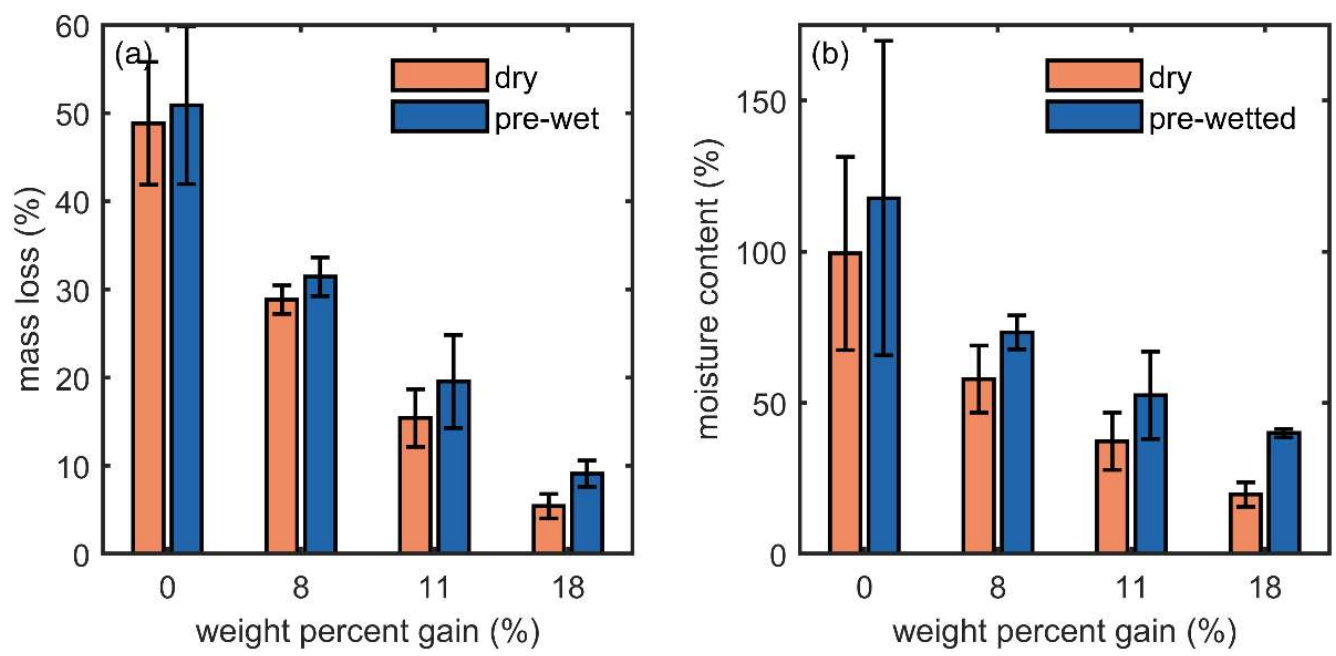

Figure 2. (a) mass loss and (b) moisture content as a function of percent weight loss from preliminary experiments where specimen pre-wetting was examined. The dry blocks had starting moisture contents (MCs) of less than 10\%, and the pre-wetted blocks had starting moisture contents between $40 \%$ and $55 \%$. Error bars represent the standard deviation from 5 replicates.

\section{Results}

\subsection{Effect of Acetylation and Soil Moisture Content}

In order to assess the effects of soil moisture on the final block $\mathrm{MC}$, a preliminary trial was conducted using the standard E10 soil bottle setup only without fungi. We refer to the moisture content from this test as $M C^{\text {ster }}$ and calculate it as:

$$
M C^{\text {ster }}=\frac{m_{\text {post }}^{\text {ster }}-m_{o d, \text { post }}^{\text {ster }}}{m_{o d, \text { pre }}^{\text {ster }}}
$$

where the superscript "ster" indicates sterile, uninoculated controls. Soil water holding capacities were varied at $110 \%, 120 \%, 140 \%$, and $150 \%$ (Figure 3). A Tukey Honest Significance Difference (HSD) test was performed on the data. For each SWHC, the $M C^{\text {ster }}$ of acetylated wood was significantly different (at $p=0.05$ ) from the untreated controls, however, the amount of acetylation did not cause significant difference in $M C^{\text {ster }}$.

These results indicate that the standard soil bottles at 130\% SWHC should achieve an MC that is well suited for fungal decay activity.

The effect of SWHC and acetylation on mass loss are presented in Figure 4. The amount of decay decreases with increasing levels of acetylation. This is not surprising as many others have demonstrated similar results [10]. Furthermore, the wood acetylated to 18\% WPG showed almost no mass loss; this is in line with previous works suggesting that wood acetylated to $20 \%$ WPG is very decay resistant $[11,21]$. The most interesting results for this investigation, however, are the results of the $8 \%$ and $11 \%$ WPG. These two levels of acetylation show measurable amounts of decay but less decay than the untreated wood. These groups will later be used to examine the interactions between acetylation, wood moisture content, and susceptibility to decay. 


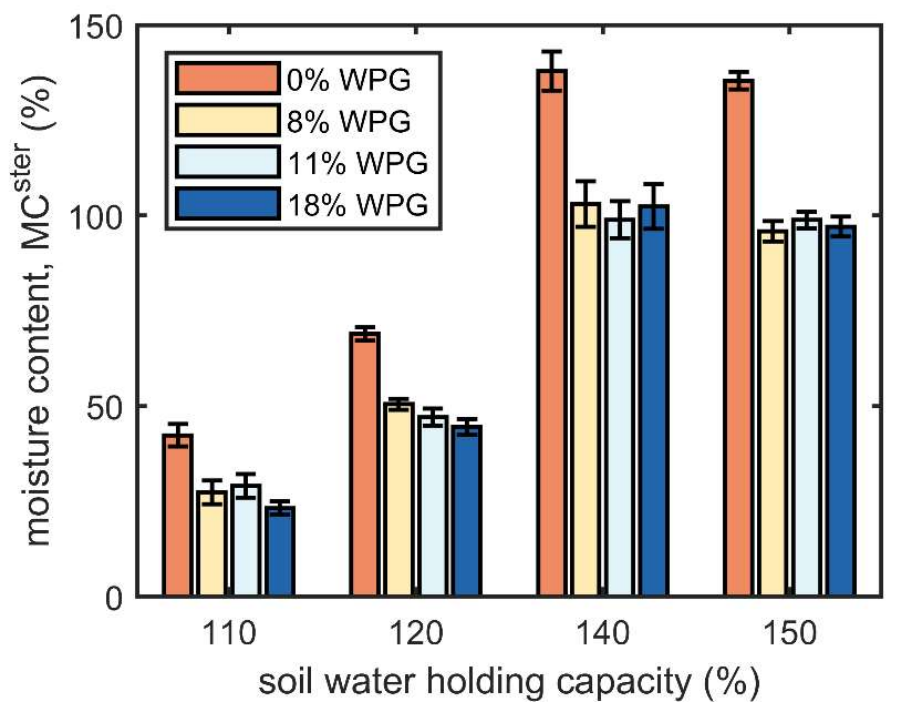

Figure 3. Effect of the soil water holding capacity on the wood moisture content after 8 weeks with no fungus present $\left(M C^{s t e r}\right)$. The error bars represent the standard deviation from five replicates.

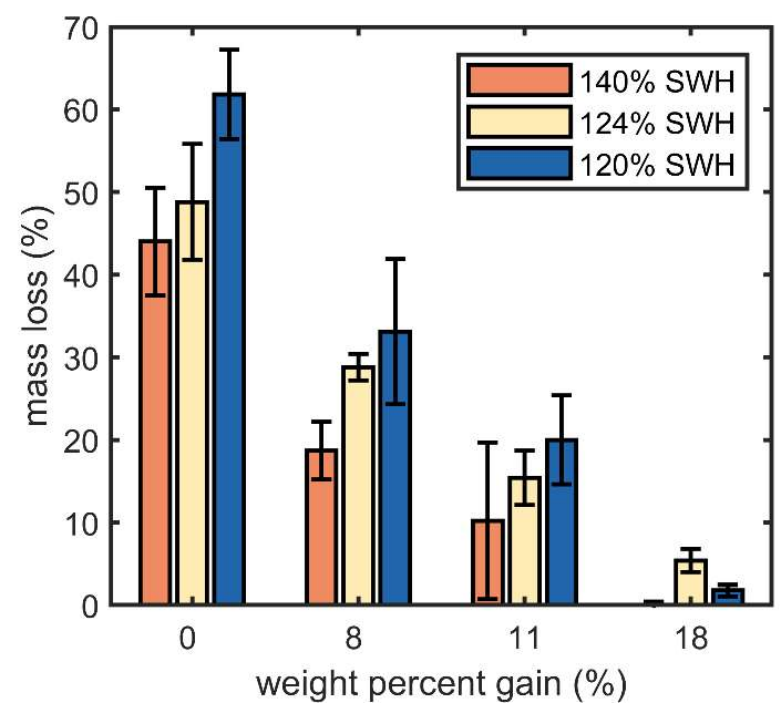

Figure 4. Percent weight loss caused by decay as a function of the soil water holding capacity and the level of acetylation. The error bars represent the standard deviation from five replicates.

The data in Figure 4 are also useful for understanding the effect of the soil moisture content on the decay fungi; for reference, the AWPA standard soil bottle test specifies $130 \%$ SWHC. For all treatments, the soil water holding capacity affected the mass loss caused by the fungus. It appears that for the three soil moisture contents examined, Rhodonia placenta is most active at $120 \%$ SWHC. For the $0 \%, 8 \%$, and $11 \%$ WPG samples, the mass loss increases with the decreasing SWHC. For the samples acetylated to $18 \%$ WPG, the $124 \%$ SWHC exhibited a higher mass loss than the $120 \%$ SWHC group $(p=0.01)$, however, all the SWHCs had a mass loss of less than $10 \%$.

\subsection{Relationships Between Moisture Content and Mass Loss}

A major motivation of this work was to understand the relationship between acetylation, wood moisture content, and decay. This is illustrated in Figure 5, which plots the mass loss against the post-test moisture content calculated three different ways. In all subfigures, the level of acetylation is plotted implicitly; the four data points correspond with the average moisture content and mass loss 
of the four levels of acetylation with the 18\% WPG specimen being the closest to the origin and the control specimen having the highest moisture content and mass loss.
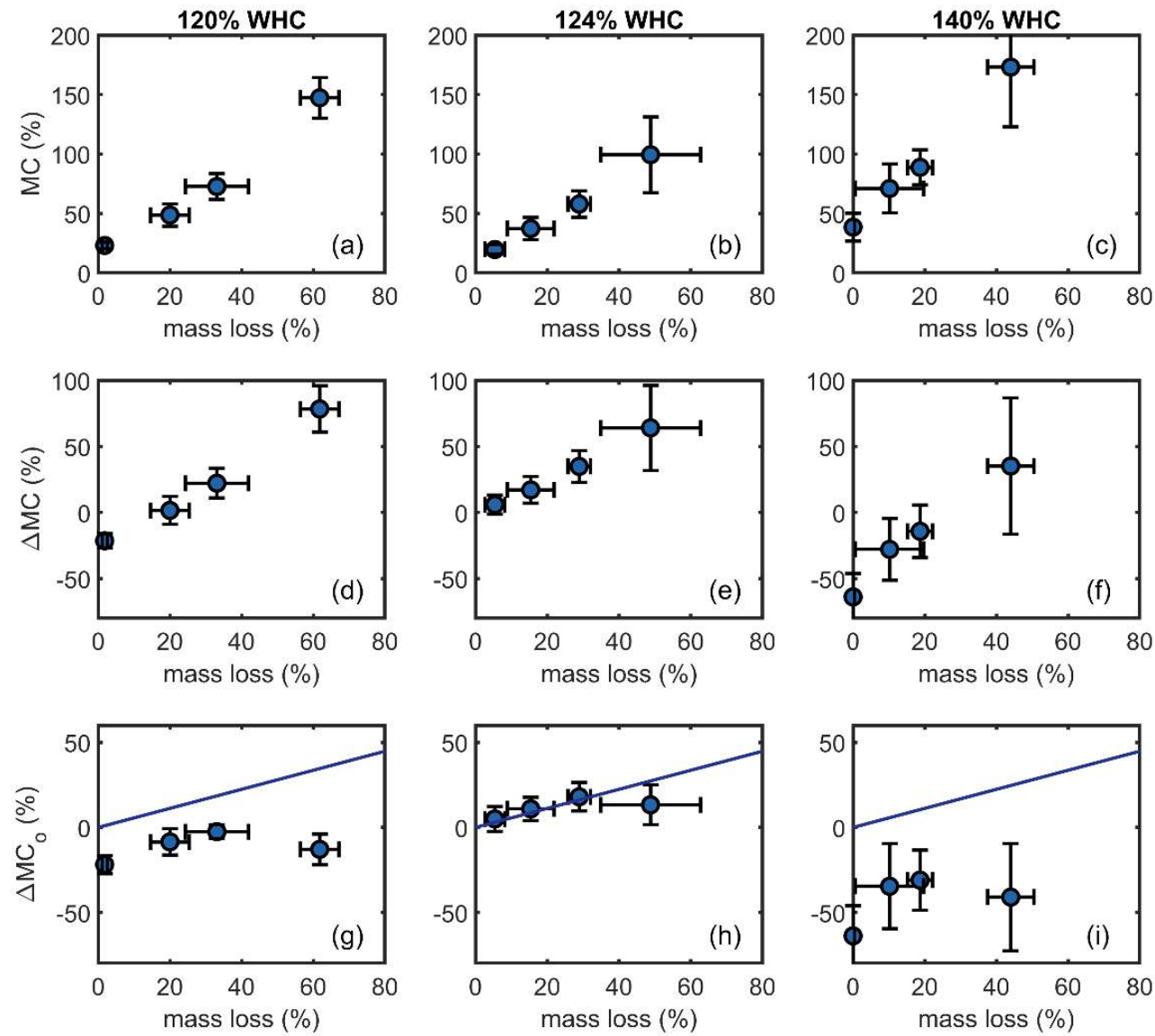

Figure 5. Relationship between mass loss and the moisture content at the end of the experiment calculated three different ways from Equations (3), (5), and (6) in rows 1, 2, and 3. The columns represent different soil water holding capacities. The error bars represent the standard deviation from five replicates.

In the first row, the data are plotted as a function of the moisture content at the end of the test calculated in the traditional manner (Equation (3)). A clear linear trend can be seen with higher mass losses having higher moisture content, similar to literature data (Figure 1c). Because the fungus that causes the mass loss itself produces water, it is not possible to determine from the data the first row whether the lower mass loss is a result of the lower wood moisture contents or whether the lower moisture contents are a result of the lower mass loss.

To examine the extra effect of fungal growth on the final moisture content, we plot " $\triangle M C$ " as a function of mass loss in the middle row of Figure 5. We define $\triangle M C$ using the following equation:

$$
\Delta M C=M C-M C^{s t e r}=\frac{m_{\text {post }}^{\text {inoc }}-m_{o d, p o s t}^{\text {inoc }}}{m_{o d, p o s t}^{\text {inoc }}}-\frac{m_{\text {post }}^{\text {ster }}-m_{o d, p o s t}^{\text {ster }}}{m_{o d, p o s t}^{\text {ster }}}
$$

where "inoc" indicates inoculated specimens and "ster" indicates sterile uninoculated controls. We are able to calculate $\triangle M C$ because we ran the identical experiment two times; once where wood was exposed to the soil bottle for 8 weeks in the absence of fungus and the second time where it was placed in the soil bottle for 8 weeks with the culture of $R$. placenta. In theory, $\triangle M C$ should represent the extra 
amount of moisture generated by the fungus beyond any changes in the wood moisture content that occur from being in contact with moist soil.

Two observations can be made from the $\triangle M C$. The first is that all samples show a linearly increasing trend with mass loss. That is, higher amounts of fungal metabolism are associated with higher final moisture contents. This is not surprising as water is a byproduct of fungal metabolism. The slope of the line in the middle column of Figure 5 cannot, however, be directly related to the stoichiometry of the metabolic reaction since the slope is in units of water per gram of post-test dry mass and the metabolic reaction can only be understood in terms of grams of water per grams of polymer consumed (mass loss and moisture content both need to be expressed with respect to pre-test dry mass).

The second, and more surprising observation from the middle row of Figure 5 is that some of the data from the $120 \%$ and $140 \%$ SWHC experiments are negative. That is, in the experiments conducted with fungus, the moisture content was lower than in the experiments without the fungus. The reason for this behavior is not clear. One potential explanation of this result is that the block was potentially inhibited from reaching the higher MC due to physiological envelopment by the fungus, thereby reducing the overall block MC. The blocks in the soil bottle begin at less than $10 \% \mathrm{MC}$ and get to $100 \%$ MC without fungus after 8 weeks of exposure in the test. This suggests that the fungus is either inhibiting the block from taking up moisture or physically excluding moisture from entering the block. Similar trends were also reported by Peterson and Cowling, where a durable species (Sitka spruce) exposed to T. versicolor exhibited a lower final moisture content (68\%) after 8 weeks in comparison to an uninoculated block (98\%) [19]. They concluded that T. versicolor can adjust the MC of the wood by the transfer of water through its own mycelium.

In short, both the plots of $\triangle M C$ and show linear trends with increasing fungal mass loss. While not surprising, it unfortunately not possible to separate out the moisture effects and acetylation from these plots. Thybring suggested that instead of examining the conventional moisture content, $M C_{O}$ should instead be analyzed. $\triangle M C_{O}$ represents the moisture generated by the fungus and, in theory, should be linearly related to the mass loss with a slope of $0.56 \mathrm{~g} \mathrm{~g}^{-1}$ [18].

We plot $\triangle M C_{O}$ as a function of mass loss in the third row of Figure 5. We define $\Delta M C_{O}$ using the following equation:

$$
\Delta M C_{O}=M C_{O}-M C^{\text {ster }}=\frac{m_{\text {post }}^{\text {inoc }}-m_{\text {od,post }}^{\text {inoc }}}{m_{\text {od,pre }}^{\text {inoc }}}-\frac{m_{\text {post }}^{\text {ster }}-m_{\text {od,post }}^{\text {ster }}}{m_{\text {od,post }}^{\text {ster }}}
$$

where the superscripts and subscripts have the same meanings as Equations (1)-(5). $\triangle M C$ is calculated here the same way as Thybring [18]. The theoretical slope of $0.56 \mathrm{~g} \mathrm{~g}^{-1}$ is shown in each of the subfigures in the third row for reference. The data roughly follow the theoretical line for the $124 \%$ SWHC condition, however, the data at $120 \%$ and $140 \%$ SWHC deviate strongly from the expected values.

It is worth further discussion of why Thybring suggested that $\Delta M C_{O}$ should be proportional to the mass loss and why this was not observed in some of our experiments. The calculations of Thybring assume that biomass is converted to water and carbon dioxide and that this extra water is maintained within the wood. Clearly, this is true instantaneously as the stoichiometry of the reaction dictates the amount of water generated by the biodegradation. However, the composition of the polymers changes during degradation becoming less hydrophilic and as degradation progresses there are more fungal hyphae in the wood which are hydrated by the fungi. Furthermore, the post-test moisture content is measured at the end of an eight-week experiment and both the fungus and the wood are passively and actively transporting moisture throughout the experiment. Peterson and Cowling have already demonstrated that fungi actively lower the wood moisture content in soil bottle experiments on unmodified wood [19]. While the relationship between $\triangle M C_{O}$ and mass loss must be true instantaneously, this analysis does not account for moisture redistribution and therefore cannot reliably predict the moisture content at the end of the test. Therefore, one possible explanation of 
the data is that some of the moisture generated by the fungus was translocated by the fungus before the end of the test. If that were the case, however, it is unclear why the data for the $124 \%$ SWHC experiment closely follow the expected behavior.

Although every effort was made to examine the effect of wood moisture content on mass loss independently of fungal moisture generation, it was not possible to separate out the effect of acetylation from fungal moisture generation and to a lesser extent fungal activity in different soil moisture contents. While higher amounts of acetylation were correlated with both lower moisture contents and lower mass losses, it is impossible to fully separate the effect of reduced hygroscopicity on decay resistance from these experiments.

\section{Conclusions}

The pre-wetting of the wood was examined as a potential way to better understand the effect of the moisture excluding properties of acetylation on the decay process. However, pre-wetting had only minor effects on the mass loss except for the 18\% WPG samples.

As observed in previous studies, the moisture content at the end of the test is linearly related to the amount of mass loss. However, it was not possible to separate out the moisture generation from the fungus from the reduced hygroscopicity of the wood for acetylated samples.

The parameter $\triangle M C_{O}$, proposed by Thybring represents the moisture generated by the fungus and should in theory be linearly proportional to mass loss [18]. While the data roughly follow the theoretical line for the $124 \%$ SWHC condition, the data at $120 \%$ and $140 \%$ SWHC deviate from the expected values. Similar deviations were also observed by Peterson and Cowling who observed that $\triangle M C_{O}$ overestimated moisture generation due to the fungus by roughly three times [19].

While the reduction in wood moisture content caused by acetylation may play a role in the decay resistance of acetylated wood, the fungus actively controls the moisture in the wood and it is not possible to independently control the wood moisture content during the decay process. Because of active water transport by the fungi, it is not possible to understand the role of moisture reduction in the decay process of acetylated wood by altering the soil bottle moisture content.

Author Contributions: Conceptualization, S.L.Z. and G.T.K..; methodology, A.B.B., S.L.Z., and G.T.K. formal analysis, S.L.Z, A.B.B., and S.V.G.; investigation, A.B.B.; writing—original draft preparation, S.L.Z.; writing-review and editing, S.L.Z., G.T.K., A.B.B., and S.V.G.; visualization, S.L.Z., A.B.B., and S.V.G. All authors have read and agreed to the published version of the manuscript.

Acknowledgments: We thank Forest Products Laboratory chemist Linda Lorenz for acetylating the samples. This work was inspired through discussions with Rebecka Ringman and Annica Pilgård of RISE (Sweden), and further refined through heated debates with Emil Thybring of the University of Copenhagen.

Conflicts of Interest: The authors declare no conflict of interest.

\section{References}

1. Hill, C.A. Wood Modification: Chemical, Thermal and other Processes; John Wiley \& Sons: West Sussex, UK, 2006; Volume 5.

2. Ringman, R.; Pilgård, A.; Brischke, C.; Richter, K. Mode of action of brown rot decay resistance in modified wood: A review. Holzforschung 2014, 68, 239-246. [CrossRef]

3. Jakes, J.E.; Plaza, N.; Stone, D.S.; Hunt, C.G.; Glass, S.V.; Zelinka, S.L. Mechanism of transport through wood cell wall polymers. J. For. Prod. Ind. 2013, 2, 10-13.

4. Jakes, J.E.; Hunt, C.G.; Zelinka, S.L.; Ciesielski, P.N.; Plaza, N.Z. Effects of Moisture on Diffusion in Unmodified Wood Cell Walls: A Phenomenological Polymer Science Approach. Forests 2019, 10, 1084. [CrossRef]

5. Zelinka, S.L.; Ringman, R.; Pilgård, A.; Thybring, E.E.; Jakes, J.E.; Richter, K. The role of chemical transport in the brown-rot decay resistance of modified wood. Int. Wood Prod. J. 2016, 7, 66-70. [CrossRef]

6. Hunt, C.G.; Zelinka, S.L.; Frihart, C.R.; Lorenz, L.; Yelle, D.; Gleber, S.-C.; Vogt, S.; Jakes, J.E. Acetylation increases relative humidity threshold for ion transport in wood cell walls-A means to understanding decay resistance. Int. Biodeterior. Biodegrad. 2018, 133, 230-237. [CrossRef] 
7. Ringman, R.; Beck, G.; Pilgård, A. The Importance of Moisture for Brown Rot Degradation of Modified Wood: A Critical Discussion. Forests 2019, 10, 522. [CrossRef]

8. Anon. CEN EN 113-Wood Preservatives Test Method for Determining the Protective Effectiveness against Wood Destroying Basidiomycetes Determination of the Toxic Values; CEN-European Committee for Standardization: Brussels, Belgium, 1996; p. 28.

9. Anon. AWPA E-10: Standard Method for Testing of Wood Preservatives by Laboratory Soil-Block Cultures; American Wood Protection Association: Selma, AL, USA, 2012.

10. Forster, S. The Decay Resistance of Chemically Modified Softwood; University of Wales: Bangor, UK, 1998.

11. Brelid, P.L.; Simonson, R.; Bergman, Ö.; Nilsson, T. Resistance of acetylated wood to biological degradation. Holz als Roh-und Werkstoff 2000, 58, 331-337. [CrossRef]

12. Hill, C.A.; Curling, S.F.; Kwon, J.H.; Marty, V. Decay resistance of acetylated and hexanoylated hardwood and softwood species exposed to Coniophora puteana. Holzforschung 2009, 63, 619-625. [CrossRef]

13. Meyer, L.; Brischke, C.; Treu, A.; Larsson-Brelid, P. Critical moisture conditions for fungal decay of modified wood by basidiomycetes as detected by pile tests. Holzforschung 2016, 70, 331-339. [CrossRef]

14. Rowell, R.M.; Ibach, R.E.; McSweeny, J.; Nilsson, T. Understanding decay resistance, dimensional stability and strength changes in heat-treated and acetylated wood. Wood Mater. Sci. Eng. 2009, 4, 14-22. [CrossRef]

15. Griffin, D. Water potential and wood-decay fungi. Annu. Rev. Phytopathol. 1977, 15, 319-329. [CrossRef]

16. Zelinka, S.L.; Glass, S.V.; Boardman, C.R.; Derome, D. Moisture storage and transport properties of preservative treated and untreated southern pine wood. Wood Mater. Sci. Eng. 2016, 11, 228-238. [CrossRef]

17. Kirker, G.T.; Bishell, A.B.; Zelinka, S.L. Electrical properties of wood colonized by Gloeophyllum trabeum. Int. Biodeterior. Biodegrad. 2016, 114, 110-115. [CrossRef]

18. Thybring, E.E. Water relations in untreated and modified wood under brown-rot and white-rot decay. Int. Biodeterior. Biodegrad. 2017, 118, 134-142. [CrossRef]

19. Peterson, C.A.; Cowling, E.B. Influence of Various Initial Moisture Contents on Decay of Sitka Spruce and and Sweetgum Sapwood by Polyporus versicolor in the Soil-Block Test. Phytopathology 1973, 63, 235-237. [CrossRef]

20. Passarini, L.; Zelinka, S.L.; Glass, S.V.; Hunt, C.G. Effect of weight percent gain and experimental method on fiber saturation point of acetylated wood determined by differential scanning calorimetry. Wood Sci. Technol. 2017, 51, 1291-1305. [CrossRef]

21. Tarkow, H. Decay Resistance of Acetylated Balsa; USDA Forest Service, Forest Products Laboratory: Madison, WI, USA, 1945.

(C) 2020 by the authors. Licensee MDPI, Basel, Switzerland. This article is an open access article distributed under the terms and conditions of the Creative Commons Attribution (CC BY) license (http://creativecommons.org/licenses/by/4.0/). 